\title{
Development of a Low Cost Eco-Friendly Minimum Quantity Lubrication System for Machining Processes
}

\author{
Arunachalam Ramanathan ${ }^{1}$, Sumaya Al Rumhi ${ }^{2}$, Noor Al Hamimi ${ }^{3, *}$ and Shurooq Al Ajmi ${ }^{1}$ \\ ${ }^{1}$ Mechanical \& Industrial Engineering Department, Sultan Qaboos University, Oman \\ ${ }^{2}$ Halliburton completion tools, Oman \\ ${ }^{3}$ Delivery Engineering Management, Petroleum Development Oman, Oman
}

\begin{abstract}
Recently all environmental worries are calling for reducing the usage of fluids in machining operations. One of the promising solutions that appeared lately is minimum quantity lubrication (MQL). This research aimed to develop an eco-friendly cooling system for a lathe machine and assess its performance. After considering the customer needs, the needs were translated into engineering specifications in the conceptual design phase, and then the quality function deployment was developed. Three concepts were generated and evaluated considering the selection criteria, and a final concept was selected using the decision matrix method. Following this, a detailed design and fabrication of the subsystems such as the oil tank and a structure accommodate all the components. The developed system was tested on six different workpiece samples to compare the MQL system with the conventional one. In general, the MQL system resulted in lower surface roughness values as well as lower tool wear.
\end{abstract}

Keywords: Minimum quantity lubrication (MQL), Vegetable oil, Machining, Cutting fluid, Tool wear, Surface roughness.

\section{INTRODUCTION}

\subsection{Introduction}

In this era of time, where the world is making efforts towards green manufacturing, it is a necessity to look for alternatives for the original coolant systems and cutting fluids used for machining. Machining is the process of changing the shape, surface, and size of materials, in chips form using a cutting tool [1]. The traditional flood coolant usually uses synthetic or mineral oil in huge amounts of volume [2], expensive to operate and maintain the system components like pumps, leaves the work space dirty with undesirable scents, and requires high level of monitoring [3]. Also, the waste of cutting fluids must be treated before disposal and exposure to them is dangerous to operators because they can cause cancers and breathing issues [4].

Dry cutting appeared to be a great alternative for flood coolant, because of the disadvantages of the usage of fluid coolants as a lubricant and coolant can be eliminated. However, this fancy idea has consequences on materials that are difficult to machine such as super alloys, etc. The cutting fluid is really doing much to the work piece as it improves the surface roughness and productivity. This happens as a

*Address correspondence to this author at Delivery Engineering Management, Petroleum Development Oman, Oman; Tel: +968 97783031;

E-mail: Noor.NZA.AlHamimi@pdo.co.om result of carrying the cutting processes at a higher feed rate, speed, and cutting depth. In addition to that, using cutting fluids tremendously reduces the power consumption, and a longer tool life is achieved because the chips and heat produced by the cutting process is removed far away from the cutting zone [4].

Despite all of these advantages of cutting fluid, the fact that it is costly, has hazardous effects to the users, and the growing attention to achieve a sustainable manufacturing processes, caused the academics and industry to re-evaluate these fluids and their benefits. Listed below are some of the approaches that were investigated [4]:

1. It is crucial to select an appropriate cutting fluid; in order to create an eco-friendly cooling systems, so there has been a shift to use vegetable and synthetic oils rather than normal oils.

2. The proper application of the fluid is important to be considered while designing the system to ensure that nothing goes to waste.

3. Series of gradual reduction in cutting fluid consumption by using dry or near dry machining. In spite of the advantages of using dry machining, the capital cost needed to start this process is enormous, as existing machines and tools are not designed to resist the high temperatures and forces produced while cutting. 
The solution to some of the issues assigned with dry machining is near dry machining (NDM), also called minimum quantity lubrication (MQL).

\subsubsection{MQL Principle}

MQL refers to the application of the smallest volume of lubricants used for metal cutting in the size of small droplets; this is done to obtain lubrication while cutting. This technology proves its ability to achieve longer tool life, better quality, great productivity rates, less waste on environment, reduces risks on operators, and lower energy consumption that result in saving costs [5]. The amount of oil provided is in the range of $10-100 \mathrm{ml} / \mathrm{h}$ that is about 1000 times less than that used for flood coolant. MQL is an alternative for the conventional coolant to minimize the cutting fluid consumption. The cutting zone is supplied with a controlled amount of oil and air mixture in the form of aerosol (mist), sprayed precisely in the cutting zone direction by a nozzle $[4,5]$. MQL system circuit is shown in Figure 1 below.

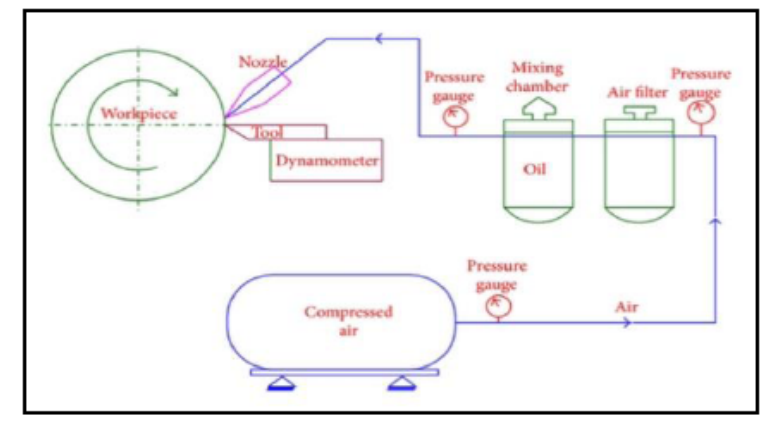

Figure 1: MQL Circuit [6].

\subsubsection{MQL Advantages}

The reason to switch coolants systems to MQL is to give the combination features of the traditional and dry coolant systems for machining and to achieve an ecofriendly process. The volume of oil is so small that the parts involved in the machining is dry. Researches have done and approved that the machining parameters are improved when using MQL rather than dry machining or flood coolant. It was found that when using MQL instead of dry machining in turning operations there will be a $5 \%$ reduction in temperatures, $10-15 \%$ for end-milling, and $20-25 \%$ for drilling. In addition, using vegetable oil as lubricant in $M Q L$ reduces the cutting force by $5-15 \%$ from the forces of dry machining. Moreover, because of the temperature reduction in the cutting zone; there is an improvement in the life of the cutting tool, and the surface finish of the workpiece. Comparing MQL with wet coolant for 4340 steel in turning, it was found that the tool chip interface temperature reduced by $5-15 \%$ in MQL [4].

\subsubsection{Problem Statement}

With the recent emphasis in developing environment friendly technologies as well as stringent norms set by Environmental agencies worldwide to reduce the use of cutting fluid used for machining operations, it becomes imperative that the conventional coolant system used in Lathe machines be replaced with appropriate eco-friendly and sustainable systems.

\subsubsection{Project Objective}

The objective of this project is to:

- Develop an Eco-friendly cooling system for a Lathe machine

- Test its performance.

\subsubsection{Expected Benefits}

Allows major reduction of machining costs by reducing the usage of fluids, longer tool life; as the mist (small amount of lubricant) will be applied directly on specified zone of the cutting tool. It also, protects environment; because the used oil is non-toxic and biodegradable. The cooling system can reduce health risks for operators; because it uses vegetable oil rather than synthetic which releases vapor that can affect the respiratory system.

\subsubsection{Motivation}

The international environmental institutes are making pressure on manufacturing industries, to emphasize their efforts on investigating technologies to reduce the environmental impacts, and find alternatives for the processes used for productions. MQL proved its ability to be a near dry machining approach that can reduce the cost, hazards on operators, and surface quality of the work piece.

\subsection{Literature Review}

\subsubsection{MQL Overview}

Minimum quantity lubrication (MQL) is a cooling system where a necessary amount of cutting fluid is produced as a mist for cooling and lubricating, at the same time the chips are removed by the compressed air. The MQL is considered as a solution for the most problems in wet machining systems and dry machining systems because it decreases the quantity of the used cutting fluid, decreases the cutting force, provides 
better surface finish, reduces the temperature of the cutting zone and makes the tool life longer [7].

MQL is also an advanced way to decrease the friction between the work piece and the cutting tool by using a little amount of fluid. The workpiece material type, the application and the cutting tool determine the required amount of fluid for lubrication. Larger size tools require more lubricant than small size tools. It was found that the tools less than $40 \mathrm{~mm}$ in diameter need $5-80 \mathrm{ml} /$ hour of lubricant fluid.

MQL is considered as near-dry process as only $2 \%$ of the fluid remains in the chips. The reduction of the fluid makes the MQL system more environmental friendly and reduces health hazards. It is the best efficient cooling system especially for open machines, micromachining, machines which stay unused for long period of time, and high speed machinery processes.

MQL system is designed to be a heat remover, lubricator and chips remover. The MQL system reduces the heat generation during cutting process Figure 2, by covering the workpiece and cutting tool interface with a thin layer of the lubricant fluid. In addition, MQL system has different techniques to remove the chips. They are compressed air, tool geometries and gravity vacuums [8].

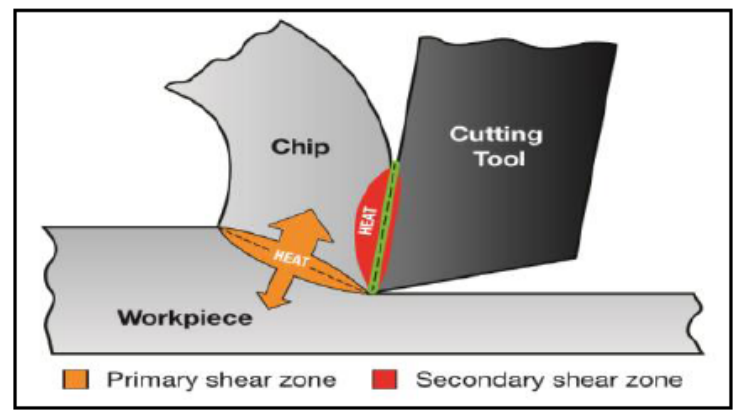

Figure 2: Heat Generation During Cutting Process [8].

\subsubsection{MQL System Parts}

MQL system consists of four main parts. The first part is the applicator; the function of the applicator is determining the amount of fluid and air produced. The second part is the output which includes the hoses, nozzle and chamber. The third part is the tooling, and this part includes the tool and tool holders, finally, the last part is the machine [8].

\subsubsection{Delivery Methods for $M Q L$}

a) External applications: when both the oil and pressurized air are blended in a chamber and then sprayed by a nozzle to the cutting area. It was found by different studies that the direction of nozzle affects the wear of the cutting tool: if the application of the mist is on the flank face rather than rake face; the wear will be reduced. Also, the nozzle distance from cutting- edge influences the uniformity of droplets distribution, as for an efficient lubrication, the particles better be in a uniform distribution [9].

b) Internal feed: In this system, the lubricant is directly supplied to the contact point through the cutting tool. The lubricant is continually available during the machining process. This continual feed can make very deep holes and high cutting speed [10]. Figure 3 shows the external and internal delivery methods for MQL.

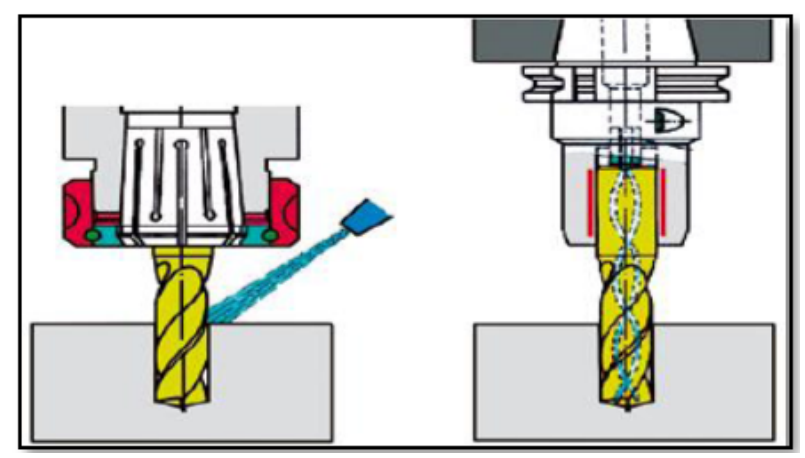

Figure 3: External and Internal Feed [10].

c) Single channel: In this system, the mist content (air and oil) is mixed in a chamber outside, and then delivered through the spindle to the machine tool. It is more efficient for machining operations than external application because the difference is that the coolant is delivered to the tooltip after going through the holder and the holes of the tool. This type of system is shown in Figure 4 below [9, 11].

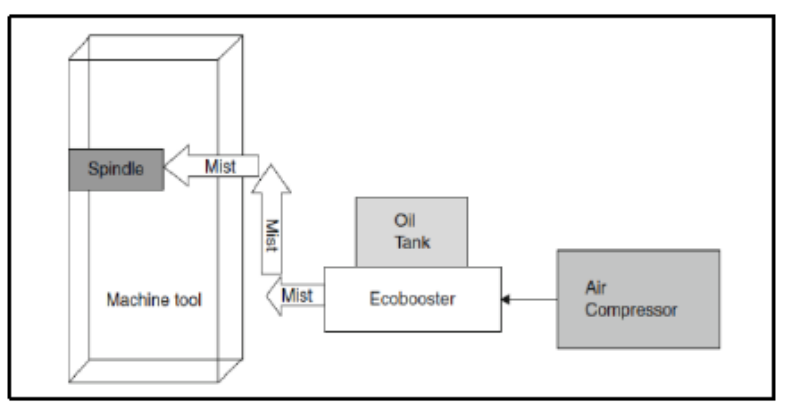

Figure 4: Single Channel [9].

d) Dual channel: Oil and air are delivered in two separate channels and then mixed at a point before the holder, as shown in Figure 5. The advantage of this system is that more mist can be applied to the cutting 
area because the oil and air are not separated because of the centrifugal force existing in the spindle rotation $[9,11]$.

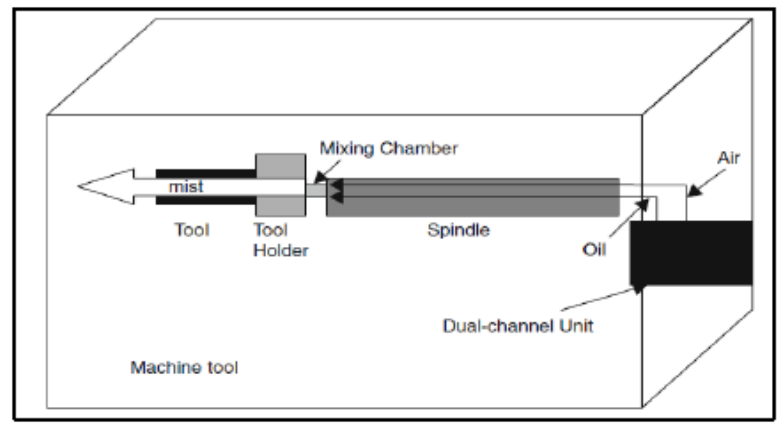

Figure 5: Dual Channel [9].

The dual channel is better than single channel because it provides a uniform spray pattern. Figure 6 shows the hose used for dual channel and Figure 7 shows the hose that is used for single channel [8].

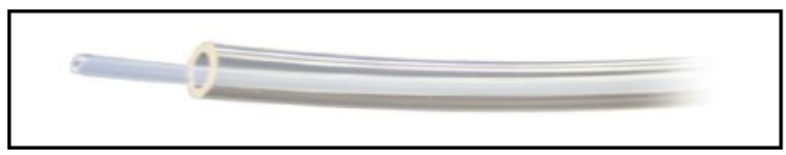

Figure 6: The Hose Used for Dual Channel [8].

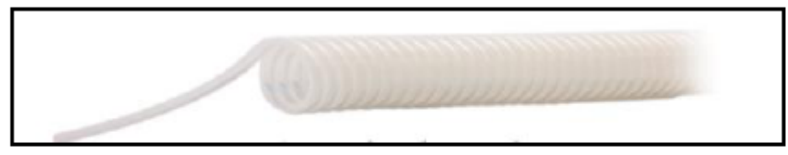

Figure 7: The Hose Used for Single Channel [8].

\subsubsection{Characteristics of Mist}

The diameter of the droplet is affected directly by the volume of oil and the air pressure. By experiments it was found that a volume of $10-300 \mathrm{ml} / \mathrm{h}$ and a pressure of 4-6 MPa create droplets of 1-3 $\mu$ in diameter. Also, the single- channel delivery method produces smaller mist droplets [9].

\subsubsection{MQL Fluid}

\subsubsection{MQL Fluid Properties}

Three significant characteristics were identified for the fluid used for MQL:

\section{Biodegradability}

2. Oxidation stability against thin film oxidation

3. Storage stability [8].

The lubricant is usually used when the work zone is under high temperature and mechanical load; the user should ensure that only environmentally friendly lubricants are used. Synthetic esters have a high boiling point, and low viscosity, this means ester oils produce much less vapor compared to conventional oils. In addition, ester oils are better in terms of biodegradability [10]. The best oil used in the minimum quantity lubrication system is vegetable oil because it reduces the cutting force by approximately $5-15 \%$ compared to the dry machining [7]. In addition, vegetable oils reduce smoke and fire hazards because they have higher flash and low volatility point. Furthermore, there will be no need for collection and disposal since the fluid supplied to the cutting zone is consumed instantly, as a result the safety is greater and the costs are lower [12].

\subsubsection{Fluid Flow}

The fluid in MQL system can be moved by three different ways. The first way is venturi based system, the second way is pressure based system; in this way a pressurized tank is used to impose the fluid to move through the system. The third way is pump based system, where the fluid is moving by a small pneumatic or electric piston pump [8].

\subsubsection{Studies on $M Q L$}

\subsubsection{Setup Design of MQL System}

The designed minimum quantity lubrication system consists of oil reservoir to store the oil, pump to pump the oil, compressor to provide compressed air, pressure gage to measure the pressure, IV set to adjust the amount of the oil from 10 to $100 \mathrm{ml} /$ hour and nozzle to provide the suitable mixing of oil and air with a high velocity.

The nozzle system consists of external nozzle, internal nozzle and a cap. The internal nozzle is for providing a high velocity air flow. The outlet of internal nozzle is connected to the inlet of the external nozzle by a cap. The external nozzle is for producing the mist [7].

\subsubsection{Water Vapor as Eco-friendly Cutting Fluid}

Inconel 718 is remarked as a difficult to cut material because of its properties that result in a poor machinability. Investigators have done experiments based on the methodology of Taguchi to improve surface roughness by using water vapor as a coolant; they used seven variables with three different levels as shown in Figure 8 below. 


\begin{tabular}{cccc}
\hline \multirow{2}{*}{ Factor (units) } & \multicolumn{3}{c}{ Levels } \\
\cline { 2 - 4 } & 1 & 2 & 3 \\
\hline Nozzle Diameter, $N_{d}(\mathrm{~mm})$ & 2 & 2.5 & 3 \\
Stand-off Distance, $S_{d}(\mathrm{~mm})$ & 20 & 30 & 40 \\
Pressure, $P$ (bar) & 1 & 1.5 & 2 \\
Valve Position, $V_{p}\left({ }^{\circ}\right)$ & 60 & 120 & 180 \\
Cutting Speed, $V_{c}(\mathrm{~m} / \mathrm{min})$ & 80 & 140 & 200 \\
Feedrate, $f(\mathrm{~mm} / \mathrm{rev})$ & 0.1 & 0.15 & 0.20 \\
Depth of Cut, $a_{p}(\mathrm{~mm})$ & 0.25 & 0.50 & 0.75 \\
\hline
\end{tabular}

Figure 8: Process Variables \& Their Levels [13].

Observations were obtained from studying parameters that affect the surface roughness, considering the water vapor as a lubricant. It was noticed that the increase of nozzle diameter leads to improve the surface finish, as the water vapor will penetrate better to the work piece. The distance between the work tool face and the tip of nozzle is called standoff distance; it is observed that the increase in standoff distance decreases the surface roughness, thus a better surface finish. In addition, the effect of increasing the pressure, the valve opening in degrees and cutting speed is leading to opposite trend for the surface finish. Also, the depth of cut and feed rate variables, increase the surface finish of the work tool by decreasing surface roughness. Using the water vapor as a cutting fluid can be a step closer to make the manufacturing processes greener [13].

\subsubsection{Applying Nano Cutting Fluid for (MQL)}

Minimum Quantity Lubrication approach is gaining significant attention in machining processes to reduce environmental loads induced by use of typical cutting fluids, Nano cutting fluid is also attracting significant attention. Grinding of $\mathrm{Ti}$ alloy by nanofluid additives (nano-Al2O3) under MQL mode were selected after considering their superior tribological properties. The experimental set up is shown below in Figure $\mathbf{9}$.

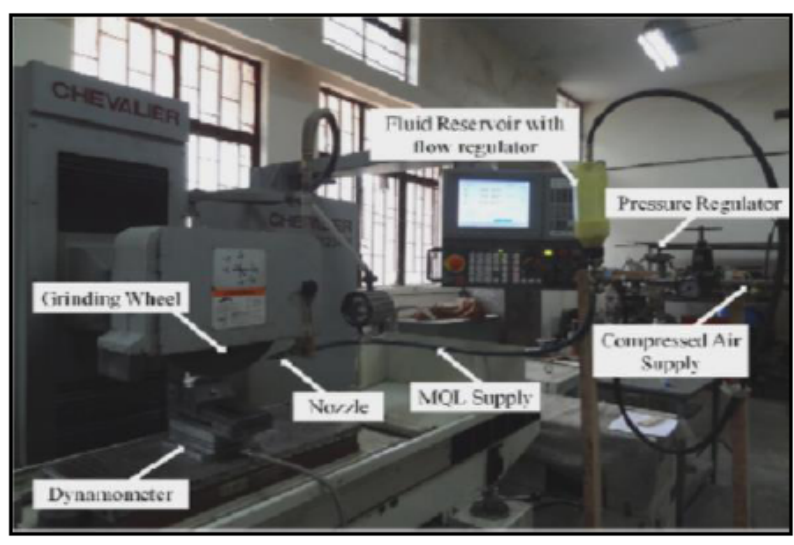

Figure 9: The Setup of the Experiment [14].
In the grinding tests, the grinding forces and surface roughness were tested in the case of nanofluid MQL with changing nanoparticles volumetric concentrations [14].

It was found that: nanoparticles in the case of nanofluid MQL were effective for significantly reducing grinding force magnitudes due to their superior lubrication effects. In addition, it was also observed that higher volumetric concentration of nanoparticles was not that effective in reducing grinding force. It was also noticed that nanofluid MQL was effective for reducing surface roughness values of ground workpieces [14].

\subsubsection{Using MQL for Grinding Titanium Alloy}

The properties of titanium alloy are high strength, light weight, and high temperature strength, Titanium is one of the most difficult materials to machine because of its low thermal conductivity, low modulus of elasticity and high chemical reactivity. Grinding machining produces high amount of heat which occurs on the surface reducing the fatigue life of the product. The coolant in MQL is supplied as a mist (a mixture of a lubricating oil and compressed air). The flow rate in MQL is about $50-500 \mathrm{ml} /$ hour, using compressed air that helps the mist to reach the grinding zone and achieve a better surface finish [15]. Below Figure 10 shows the set up to test the MQL system for grinding $\mathrm{Ti}$.

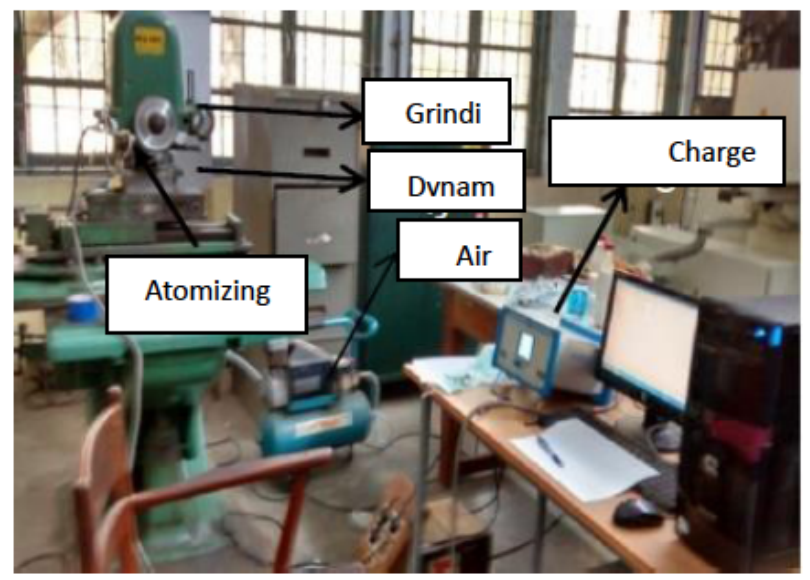

Figure 10: MQL Grinding Set-up [15].

The coolant tank is placed at a height higher than the nozzle. The coolant goes down in the nozzle due to the pressure caused by the injected compressed air. A coolant flow rate valve regulates the coolant with the compressed air. In the atomizing nozzle, the liquid and the compressed air are mixed in the nozzle to produce the mist. The results were great; the MQL condition 
produces better grinding performance, lower surface roughness, and good surface texture [15].

\section{MATERIALS AND METHODS}

\subsection{MQL System Design}

Figure 11 below shows the developed design for the MQL system. A compressor provides pressurized air to the oil tank to force the oil to flow through the proportional flow valve to provide different levels of flow. The controlled amount of oil will flow then to a non-return valve to prevent the back flow. After that it will go to one inlet of the nozzle, to be mixed with the air coming directly from the manual pressure regulator which is also controlled by a stepper motor to provide different pressure values. Then, the nozzle will spray mist to the cutting zone and the work piece.

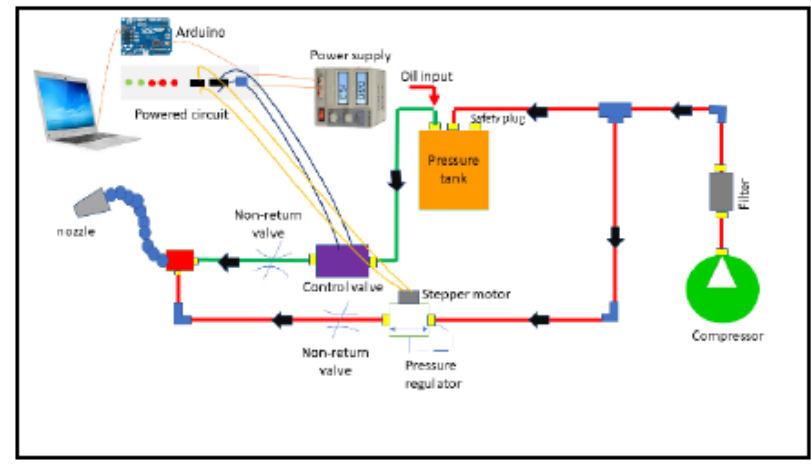

Figure 11: MQL System Design.

\subsection{Materials}

Table below lists all the material that were used to fabricate the MQL system.

\subsection{Fabrication}

\subsubsection{Oil Tank}

For the MQL system it is required to have a tank that can hold the oil used for lubrication. The volume of this tank is based on the required amount that can provide lubricant for a sufficient time. It was found that one liter of volume is good for this system. The available pipe found in the workshop was $150 \mathrm{~mm}$ in high, $218 \mathrm{~mm}$ in diameter and $8 \mathrm{~mm}$ in thickness, so the volume is calculated as follow:

$$
\begin{aligned}
V & =\pi r \quad 1^{2} h \\
V & =\pi \times 101^{2} \times 150 \\
& =4804671 \mathrm{~mm}^{3}=4.8 \mathrm{~L}
\end{aligned}
$$

About 4.8 liter is sufficient for testing the performance of this MQL system.

Table 1: $\quad$ The Material

\begin{tabular}{lc|}
\hline Component & Quantity \\
\hline Push-in-fitting & 13 \\
\hline T joint & 2 \\
\hline Elbow & 3 \\
\hline Socket & $1.5 \mathrm{~m}$ \\
\hline Tube & 1 \\
\hline FRL unit & 1 \\
\hline Nozzle & 2 \\
\hline Non-return valve & 1 \\
\hline Pressure regulator & 1 \\
\hline Compressor & 1 \\
\hline Proportional valve & 1 \\
\hline Stepper motor & 1 \\
\hline Arduino UNO & 1 \\
\hline Oil tank & 1 \\
\hline Power supply+ adaptor & 6 \\
\hline Push buttons & 1 \\
\hline Driver & 1 \\
\hline 3D Printed shaft & 5 \\
\hline Hydraulic adaptor & 1 \\
\hline Manual control valve & \\
\hline
\end{tabular}

\subsubsection{Structure}

A structure was designed to accommodate all the components of the MQL system. Figure 12 shows the manufactured structure. It's provieded with a wheels to be a portable system.

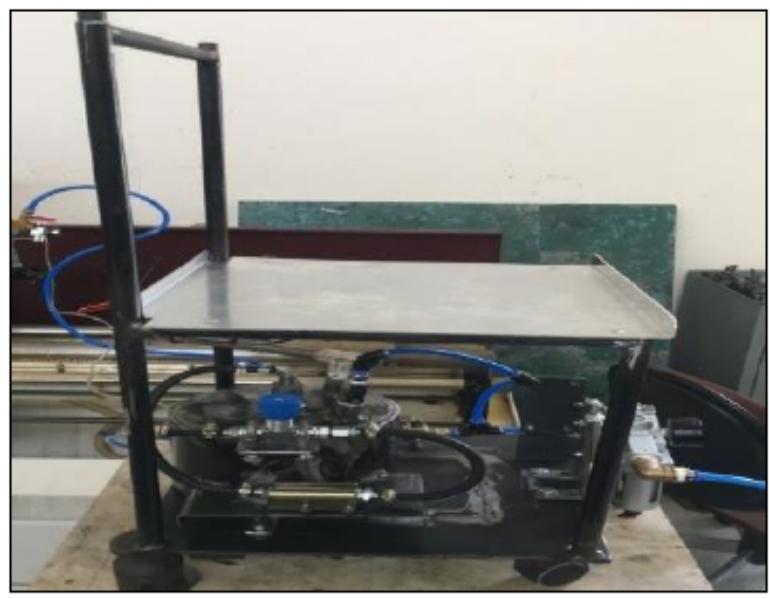

Figure 12: Manufactured Structure. 


\subsubsection{Control System}

The MQL system is fully controlled, where the pressure and the flow rate in the system are adjusted by the operator using push-buttons. Each push-button provides a certain level for the flow rate or for the pressure, and one push-button is to turn the system on or off. For controlling the flow rate, a proportional flow control valve is used with an Arduino Uno controller. The connections are as in the figure below. The green wire of the proportional control valve was connected to pin 11 of the Arduino, which was programmed as an output. It provides a pulse width modulation signal (PWM) to control the opening angle of the valve, and the red wire was connected to the positive voltage of the power supply, and the black wire was connected to the negative voltage of the power supply. The power supply was adjusted to $12 \mathrm{~V}$. The two push buttons were connected to pins 7 and 6 that were programmed as inputs. The program instructions are as follow:

- When the first push button is pressed, pin 11 will provide PWM signal that will allows the valve to open $1 / 4$ of the full open. This will provide a flow rate range from $54.54 \mathrm{ml} / \mathrm{hr}$ to $85.72 \mathrm{ml} / \mathrm{hr}$ in the system.

- When the second push button is pressed, pin 11 will provide PWM signal that will allows the valve to open $1 / 2$ of the full open. This will provides a flow rate of range $222.22 \mathrm{ml} / \mathrm{hr}$ to $472.44 \mathrm{ml} / \mathrm{hr}$ in the system.

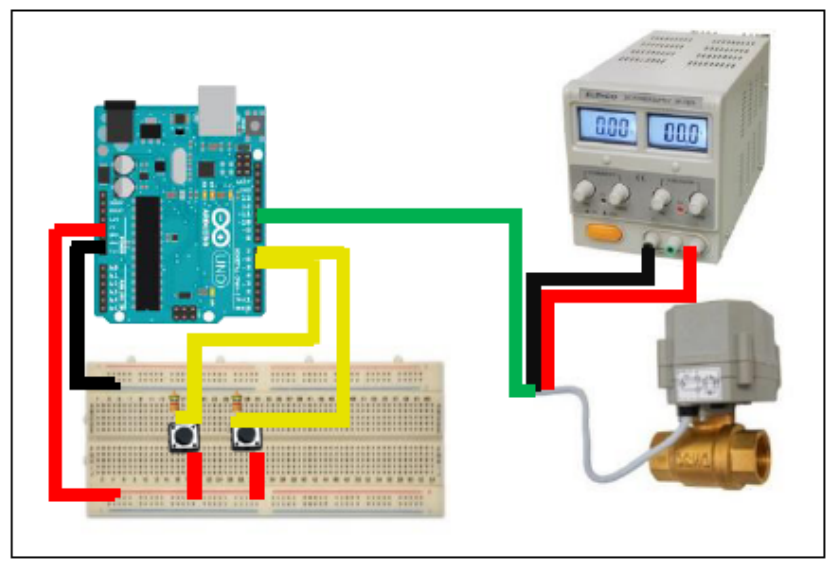

Figure 13: The Connections for Flow Rate Control.

For controlling the pressure, the better way was to use a proportional pressure regulator, but it is pricy and because of the budget constraint, another way was used to control the pressure in the system. A manual pressure regulator was converted to an electromechanical one by the following steps:
1- a manual pressure regulator was bought according to the required specifications.

2- stepper motor with high torque was selected. Its specifications were chosen according to its ability to rotate the manual pressure regulator.

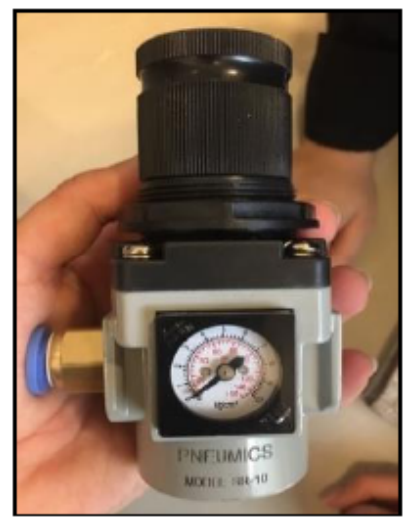

Figure 14: The Manual Pressure Regulator.

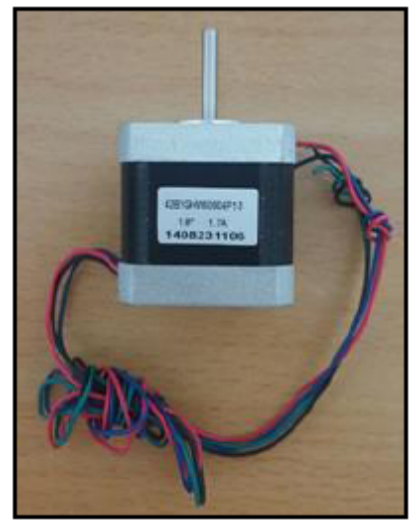

Figure 15: Stepper Motor.

3- an interface was designed to connect the stepper motor shaft to the knob of the pressure regulator. Then the design was printed using $3 \mathrm{D}$ printer.

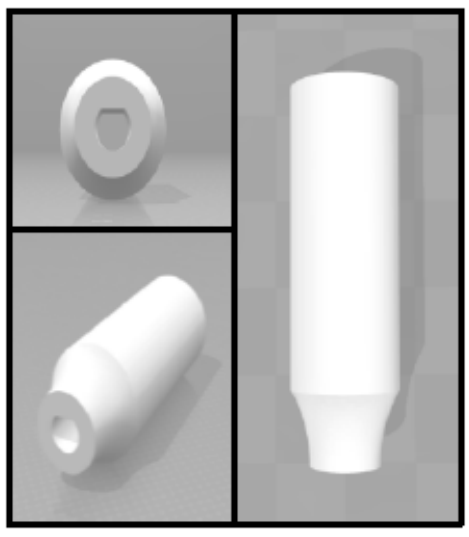

Figure 16: 3D Drawing for the Interface. 


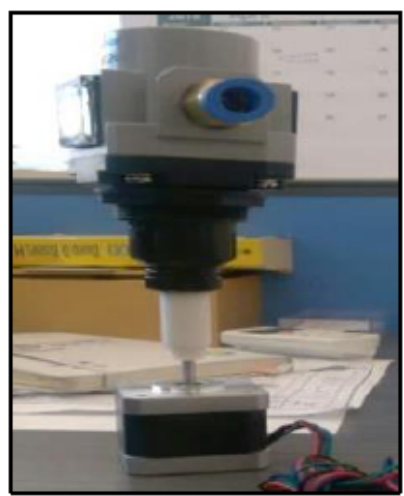

Figure 17: The Pressure Regulator Connected to the Stepper Motor.

The control circuit for the stepper motor was connected as shown in the figure below. The L293D motor driver was used to drive the stepper motor. The four wires of the stepper motor were connected to the output pins of the driver. The input pins of the driver were connected to the output pins of the Arduino. The pin number 8 in the driver chip was connected the power supply. The power supply was adjusted to $12 \mathrm{~V}$.

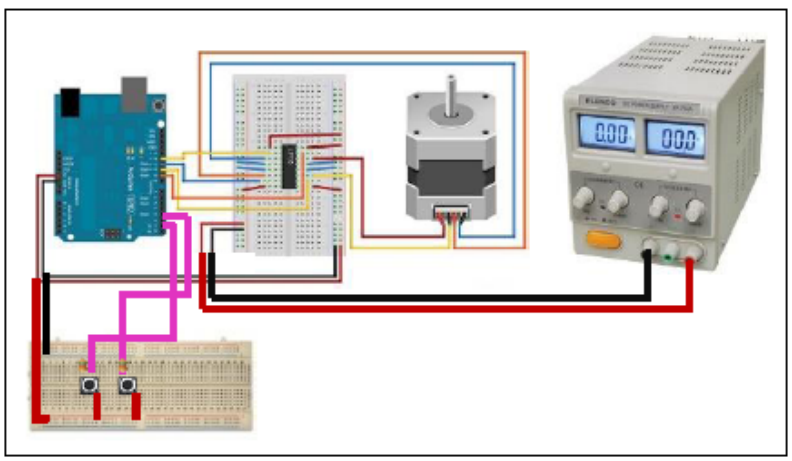

Figure 18: The Connection for Stepper Motor Control.

To provide a full control for the MQL system (control the flow rate and the pressure), an integration between the flow control valve circuit and the stepper motor circuit was done. The final circuit is as shown below.

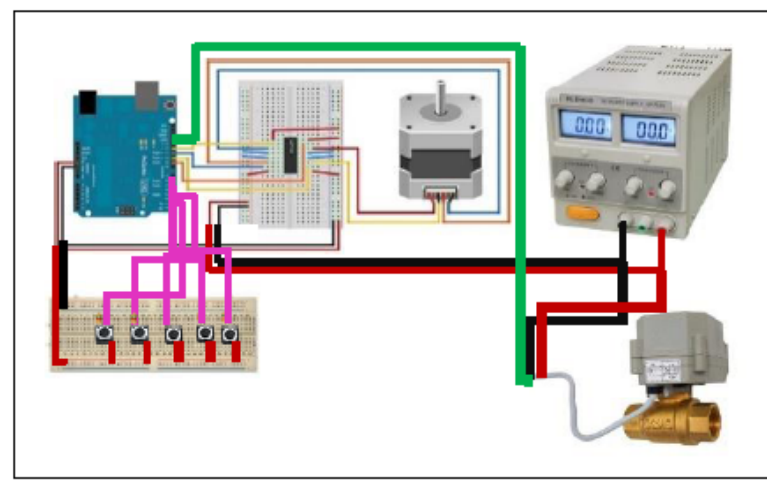

Figure 19: The Full Control Connections for MQL System.

\subsection{Testing}

The MQL system was positioned close to a lathe machine as shown in Figure 20. The tip of the nozzle was focused on the workpiece and cutting tool as can be seen in Figure 21. The lathe machine was turned on, and its feed rate was set at $0.25 \mathrm{~mm} / \mathrm{rev}$, cutting speed at $125 \mathrm{rpm}$ and depth of cut to $2 \mathrm{~mm}$. The tools that were used are high carbon steel and 6 mild steel specimens were prepared of length of $60 \mathrm{~mm}$ and diameter of $20 \mathrm{~mm}$. six experiments were done based on the design of experiment table below. The first one is dry turning, where the turning was done without using any lubrication. The second experiment is using the flood traditional coolant. Then the MQL system was tested for four different cases as show in table, and the chips were collected. Finally, the roughness of specimens and wear of cutting tools was measured and chips were compared.

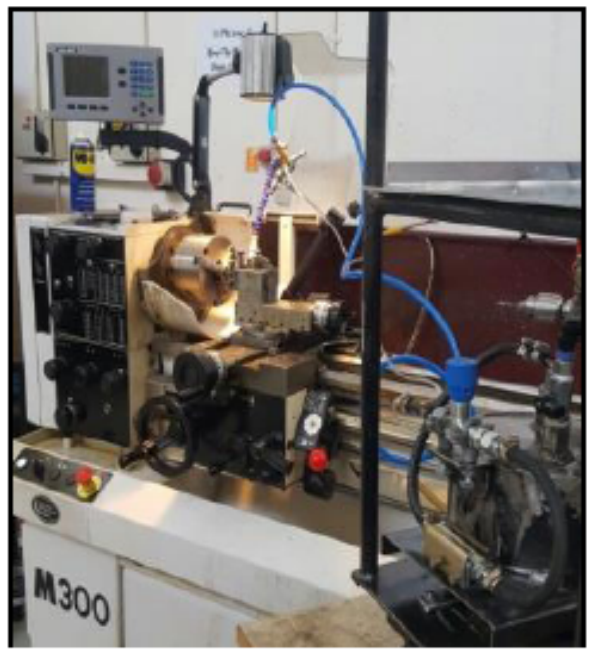

Figure 20: MQL System in the Lathe Machine.

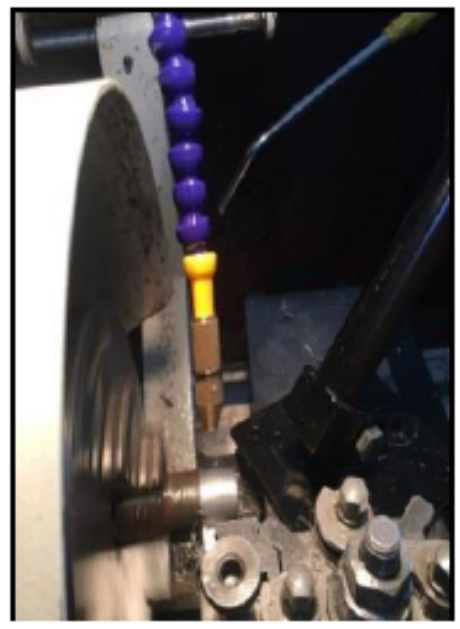

Figure 21: Nozzle Tip Facing the Cutting Zone. 


\section{RESULTS}

\subsection{Surface Roughness}

Portable measurement device (Mar Surf M300) was the instrument used to measure to surface roughness.

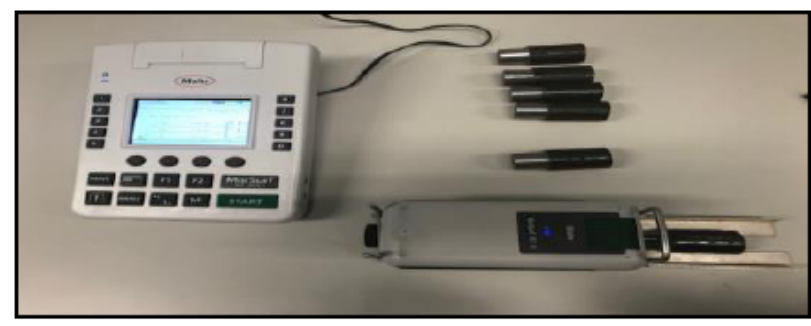

Figure 22: Surface Roughness Value for One Sample.

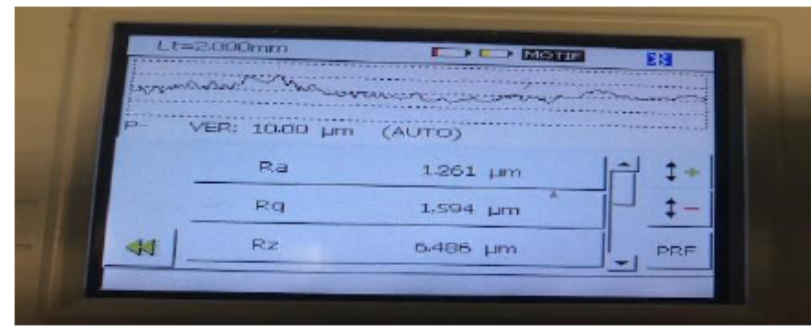

Figure 23: Roughness Measurement Setup.

The surface roughness $\mathrm{Ra}$ was measured after completion of the six experiments as shown in Figure 13 and Figure 14, using a stylus that have a tip radius of $2 \mu \mathrm{m}$, three readings for each specimen was taken, and average is reported in the table below:

Table 2: $\quad$ Surface Roughness Ra Values

\begin{tabular}{|ccc|}
\hline Specimen & $\begin{array}{c}\text { Type of } \\
\text { lubrication }\end{array}$ & $\begin{array}{c}\text { Surface } \\
\text { roughness } \\
\text { Ra ( } 1 \text { m) }\end{array}$ \\
\hline B & $\begin{array}{c}\text { Traditional } \\
\text { coolant }\end{array}$ & 2.158 \\
\hline C & MQL, case1 & 1.398 \\
\hline D & MQL, case2 & 1.296 \\
\hline E & MQL, case3 & 1.238 \\
\hline F & MQL, case4 & 1.127 \\
\hline
\end{tabular}

A bar chart is made to illustrate the error between the three different readings as it can be seen in Figure 24 below.

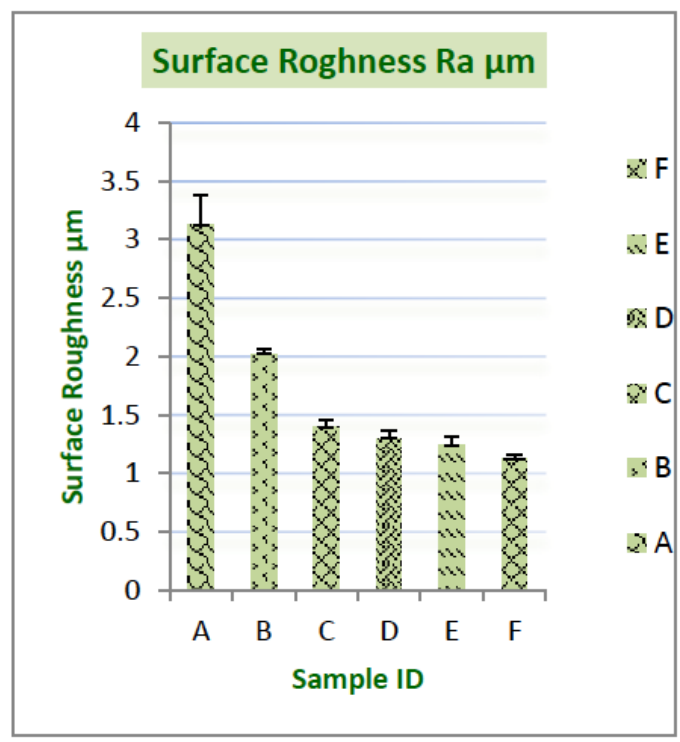

Figure 24: Surface Roughness Chart.

Furthermore, chips were collected from the turning processes that were done for the six experiments. Figure 25 shows the chips.

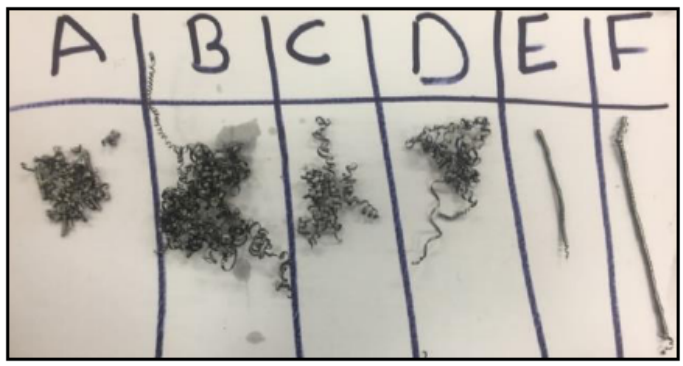

Figure 25: Chip Collected from the Turning Process.

\subsection{Tool Wear Measurement}

Tool wear causes tool failure. The tool wear has a strong effect on dimensional accuracy and surface finish. Tool will wear out if the temperature is high. So it is a must to bring the temperature down or the tool will soften and its shape will change.

Also, high temperature leads to difussion wear, so from the workpiece material or from the tool material ions can migrate.

Failure ocurs at three locations of a cutting tool, and ccordingly there are three types of wear: Flank wear, Crater wear and Corner wear. Table 3 shows images of the flank wear, under dry, traditional cooling and MQL conditions. The images were taken by a microscope. Then by magnifing the image the length where the were happened was measured. It is clear that flank were growth rate decreased by MQL. 
Table 3: $\quad$ Tool Wear Measurement Results

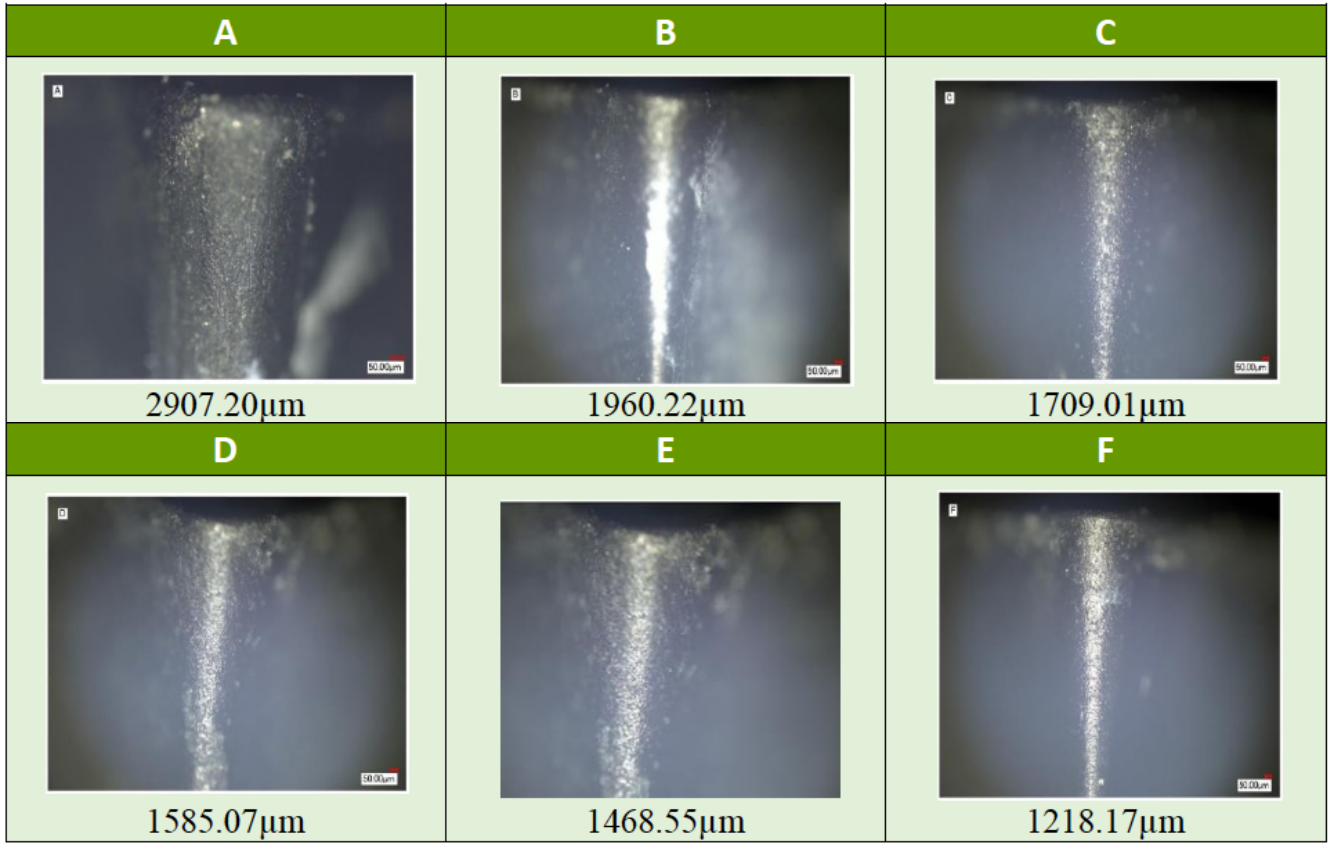

\section{DISCUSSION}

\subsection{Surface Roughness}

Our results demonstrated that the MQL system reduced the surface roughness compared to the dry turning and the traditional one. As it can be seen obviously that dry cutting results in the highest $\mathrm{Ra}$. When using Dry turning sample (A), the surface roughness reading indicated high values with an average of $3.158 \mu \mathrm{m}$ which is quite high, which could be because of the higher heat generated in the cutting zone, resulting in smearing the workpiece material. Sample (B) represented the traditional coolant used in the workshop, and the average measured surface roughness was 2.021, which in comparison to the specimen that used MQL is still high.

When using minimum quantity lubricating, case 4 (higher pressure and higher flow rate), produced a specimen with lower surface roughness values with an average of $1.127 \mu \mathrm{m}$. The results of the experiment found clear support that this happened because the mist reached the shear zone where the tool comes in contact with the workpiece, to prevent shearing. Using normal flood coolant will not reach that zone as it is not pressurized to penetrate into it.

To identify the factor that affects more on the surface roughness, the Minitab software was used. Flow level and pressure were taken as factors as shown in Figure $\mathbf{2 6}$ below. It was found that pressure influences the surface roughness; higher pressure resulted in lower surface roughness. This is because the pressure is effective to make the mist penetrate to the shear zone where the temperature is higher. Figure 27 shows the Preto chart where $B$ represents the pressure factor and it is higher in effectiveness than the flow level factor.

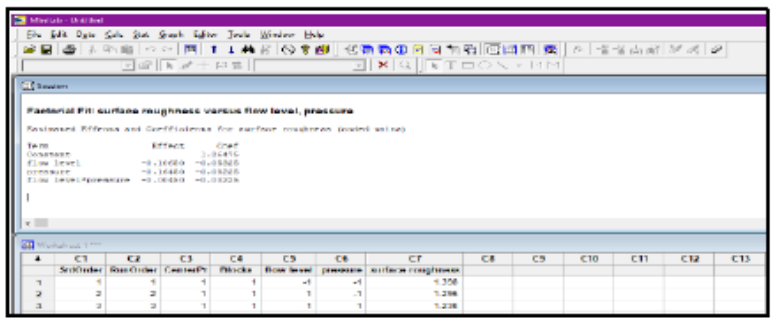

Figure 26: Minitab Factorial Fit.

In addition a difference can be identified between the chips. Figure 25 shows that traditional coolant produced serrated chips compared to the MQL chips. Which were continuous and smooth indicating a smooth shearing because of the better lubrication in MQL.

\subsection{Tool Wear Measurement}

The results of the test shows that for dry turning the tool wear was very obvious and its measured length was $2907.20 \mu \mathrm{m}$, also there was some material that was adhering to the tool. The tools which were used with the MQL system had a flank wear of less than $1709.01 \mu \mathrm{m}$, which is about $40 \%$ lesss than the dry one. 


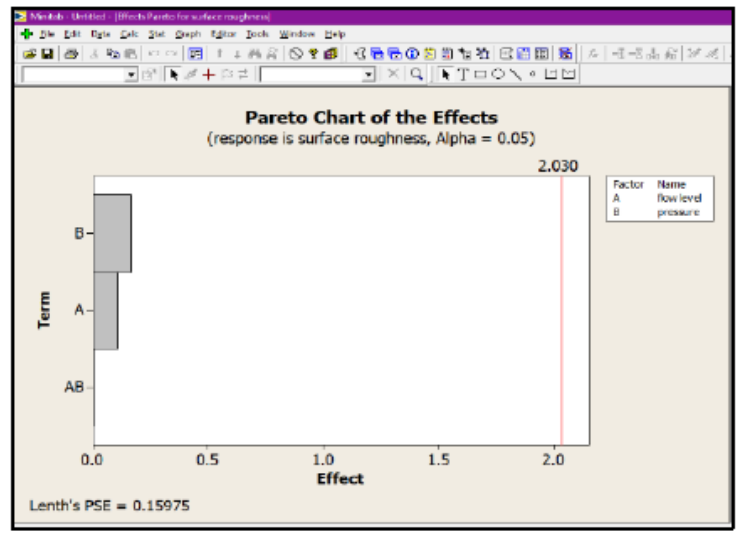

Figure 27: Microscope Used to Measure the Tool Wear.

The cause of reduction in flank wear be attributed to reduction in the flank temperature by $M Q L$, that helped in reducing wear by retaining tool hardness. The flank tool wear governs the surface finish and dimensional accuracy. Irregular and higher flank wear leads to poor surface finish and dimensional accuracy. The application of MQL has reduced the flank wear, which provided better surface finish for the workpiece.

\section{CONCLUSIONS}

A MQL system was developed that can reduce the surface roughness of the workpiece, increase tool life, reduces the cost and environmental impacts, and it can be used easily by operators. After conducting a literature review about the major topics related to the system. The review started with an overview about $M Q L$ by identifying the system parts, and then the delivery methods and the mist characteristics were specified. The MQL fluid was a significant topic; it requires special properties and different delivery methods. The system was fabricated and tested and it proved its ability to reduce the surface roughness of the workpiece as well as reducing the wear of the tool. Also, it produced a clean work place.

\section{REFERENCES}

[1] http://www.public.iastate.edu/ mebbs/courses/ME322/Machi ning.html.
[2] Nourredine Boubekri, Vasim Shaikh, Minimum Quantity Lubrication (MQL) in Machining: Benefits and Drawbacks, Journal of Industrial and Intelligent Information 2015; 3(3). https://doi.org/10.12720/jiii.3.3.205-209

[3] Samatham Madhukar, Aitha Shravan, Pakka Vidyanand and G.Sreeram Reddy, (Oct 2016) , A Critical review on Minimum Quantity Lubrication (MQL) Coolant System for Machining Operations, India.

[4] Chakraborty, S.Behera, Dinesh, Ghosh, 2013, Investigations on the Effects of Minimum Quantity Lubrication on Surface Roughness and Cutting Force during Turning of Bearing Steel.

[5] Bruce L. Taia, David A. Stephensonb, Richard J. Furnessb, Albert J. Shiha, 2014, Minimum Quantity Lubrication (MQL) in Automotive Powertrain Machining, USA.

[6] https://www.researchgate.net/figure/258392307_fig4_Minimu m-quantity-lubrication-circuit.

[7] Mr. Saurav Chakraborty, 2016, Design, Fabricatin and Application of Minimum Quantity Lubrication (Mql) Setup in Machining Essay, Department of Mechanical Engineering, Indian Institute of Technology, Delhi.

[8] Tim Walker, UNIST, 2015, The MQL Handbook (a guide to machining with minimum quantity lubrication).

[9] Sheri Kurgin, 2010, Minimum Quantity Lubrication (MQL) During Machining of Automotive Components, General Motors Powertrain Headquarters, Pontiac, MI, USA.

[10] Minimum quantity lubrication for machining operations, November 2010, Deutsche Gesetzliche Unfallversicherung (DGUV).

[11] T. Aoyama, Development of a mixture supply system for machining with minimal quantity lubrication. Ann. CIRP 2002; 51(1): 289-292. https://doi.org/10.1016/S0007-8506(07)61519-4

[12] Dr. Uday S. Dixit, Dr. R. Ganesh Narayana, n Dr. M. Ravi Sankar, 2014, 5th International and 26th All India Manufacturing Technology, Design and Research Conference, Department of Mechanical \& Industrial Engineering Indian Institute of Technology Roorkee.

[13] Ganesh S. Kadam. Raju S. Pawade, 30-09-2017, Water Vapour as Eco-friendly Cutting Fluid - Parametric Explorations in HSM of Inconel 718, Department of Mechanical Engineering, Dr. Babasaheb Ambedkar. Technological. University, Lonere, Raigad 402103, M.S., India.

[14] Dinesh Setti, Sudarasan Ghosh, and P. Venkateswara Rao, 2012, Application of Nano Cutting Fluid under Minimum Quantity Lubrication (MQL) Technique to Improve Grinding of $\mathrm{Ti}$ - 6Al - 4V Alloy, Engineering and Technology International Journal of Mechanical and Mechatronics Engineering.

[15] Monith Biswojyothi, A.S.S. Balan, N. Arunachalam, L. Vijayaraghavan, 2014, A study on the minimum quantity lubrication in Grinding of Titanium alloy (TI-6AI-4V), Manufacturing Engineering Section, Department of Mechanical Engineering, IIT Madras, Chennai-36.

\section{DOI: https://doi.org/10.31875/2409-9848.2021.08.5}

(c) 2021 Ramanathan et al.; Zeal Press.

This is an open access article licensed under the terms of the Creative Commons Attribution Non-Commercial License (http://creativecommons.org/licenses/by-nc/3.0/), which permits unrestricted, non-commercial use, distribution and reproduction in any medium, provided the work is properly cited. 